\title{
CONSILIUM
}

Berkala Kajian Konseling Dan Ilmu Keagamaan

Avalaible at http://jurnal.uinsu.ac.id/index.php/consilium

ISSN : 2338-0608 (Print) | ISSN : 2654-878X (Online)

\section{Efektivitas Konseling Cognitive Behavior Therapy Dalam Meningkatkan Kontrol Diri Siswa}

\author{
Cici Yulia \\ Universitas Muhammadiyah Prof Dr Hamka, DKI. Jakarta, Indonesia. \\ Korespondensi: ciciyulia@uhamka.ac.id
}

\begin{abstract}
Self-control is one of the main potential of the students must be developed. Inability to control themselves students in school resulted in the emergence of uncontrolled behavior as, breaking the school rules, undiscipline in the learning process at school. Aspects of self-control that should be developed by the students is the behavior control, control the mind (cognitive control), and control the decision (decisional control). This study aims to determine: (1) a picture of the self-control of students before and after a given cognitive behavior therapy approach; (2) the effectiveness of cognitive behavior therapy approach to increase self-control. The experimental research design with one group pretest-posttest design aims to test whether cognitive behavior therapy counseling approach with the group format can enhance students' self-control to be high. One group was selected using a technique using non-random sampling with purposive sampling method chosen from the Kelas $X$ Teknik Kendaraan Ringan (TKR) SMKN 1 Koto Baru Dharmasraya. group consisted of 10 students. cognitive behavior therapy group counseling held during five meetings. Data on self-control are collected through the pretest and posttest, then analyzed using the Wilcoxon Signed Ranks Test with SPSS version 20.00 .
\end{abstract}

Keywords: Self Control, Cognitive Behavior Therapy Apporach.

\begin{abstract}
Abstrak: Kontrol diri merupakan salah satu potensi yang dimiliki oleh siswa yang harus dikembangkan. Ketidakmampuan siswa dalam mengontrol diri di sekolah berakibat munculnya perilaku yang tidak terkontrol seperti, melanggar aturan sekolah, tidak tertib dalam proses pembelajaran di sekolah. Aspek kontrol diri yang perlu dikembangkan oleh siswa adalah kontrol perilaku (behavior control), mengontrol pikiran (cognitive control), dan mengontrol keputusan (decisional control). Penelitian ini bertujuan untuk mengetahui: (1) gambaran kondisi rata-rata skor kontrol diri siswa sebelum dan setelah diberikan pendekatan cognitive behavior therapy; (2) efektifitas pendekatan cognitive behavior therapy untuk meningkatkan kontrol diri. Penelitian eksperimental dengan rancangan The One Group Pretest-Posttest Design ini bertujuan untuk menguji apakah konseling cognitive behavior therapy dengan format kelompok dapat meningkatkan kontrol diri siswa menjadi tinggi. Satu kelompok dipilih menggunakan menggunakan teknik non-random sampling dengan metode purposive sampling yang terpilih dari siswa kelas $\mathrm{X}$ Jurusan Teknik Kendaraan Ringan (TKR) SMK Negeri 1 Koto Baru Dharmasraya, kelompok terdiri dari 10 orang siswa. bimbingan kelompok cognitive behavior therapy diadakan selama lima kali pertemuan. Data tentang kontrol diri dikumpulkan melalui pretest dan posttest, kemu dian dianalisis dengan menggunakan Wilcoxon Signed Ranks Test dengan bantuan SPSS versi 20.00.
\end{abstract}

Kata kunci: Kontrol Diri, Konseling Cognitive Behavior Therapy. 


\section{PENDAHULUAN}

$\mathrm{K}$

ontrol diri merupakan satu potensi yang dapat dikembangkan dan digunakan individu dalam proses kehidupan, termasuk dalam menghadapi Lkondisi yang terdapat di lingkungan sekitarnya.Kontrol diri memiliki makna sebagai suatu kecakapan individu dalam kepekaan membaca situasi diri dan lingkungannya serta kemampuan untuk mengontrol dan mengelola faktor-faktor perilaku sesuai dengan situasi dan kondisi untuk menampilkan diri dalam melakukan sosialisasi (Calhoun danAcocella, 1990). Perkembangan control diri(self control) pada dasarnya seiring dengan bertambahnya usia seseorang. Semakin dewasa individu diharapkan mempunyai control diri (self control) yang lebih baik dibanding saat remaja dan anak-anak. Namun demikian, beberapa kasus menunjukkan hal yang sebaliknya, dimana beberapa permasalahan tersebut juga dilakukan oleh orang yang sudah dewasa.

Borba (2008) menjelaskan control diri(self control) merupakan pengendalian pikiran serta tindakan agar dapat menahan dorongan dari dalam maupun dari luar sehingga dapat bertindak dengan benar. Goldfried dan Merbaum (dalam Gufron dan Risnawati, 2010).mendefinisikan control diri sebagai suatu kemampuan untuk menyusun, membimbing, mengatur dan mengarahkan bentuk perilaku yang dapat membawa individu ke arah konsekuensi positif.

Mengembangkan kemampuan mengontrol diri yang baik, individu menjadi pribadi yang efektif, hidup lebih konstruktif, mampu menyusun tindakan yang berdimensi jangka panjang, serta menerima diri sendiri dan diterima oleh masyarakat luas.Kemampuan mengendalikan diri menjadi sangat berarti untuk meminimalkan perilaku buruk yang selama ini banyak dijumpai.

Kemampuan menumbuh kembangkan potensi control diri dalam diri individu yakni dimulai dari lingkungan sekitar, didikan orangtua, teman, masyarakat serta ranah pendidikan baik non-formal maupun informal. Ini diperkuat oleh Undang-Undang dan Peraturan Pemerintahan RI tentang Pendidikan No. 20 Tahun 2003 yang mendefenisikan bahwa pendidikan adalah usaha sadar dan terencana demi mewujudkan suasana belajar dan proses pembelajaran agar peserta didik secara aktif dapat mengembangan potensi dirinya untuk memiliki kekuatan spiritual keagamaan, pengendalian diri, kepribadian, kecerdasan, dan akhlak mulia. Defenisi di atas terlihat jelas bahwa proses pendidikan di Indonesia membantu mewujudkan peserta didik yang mampu mengembangkan potensi control diri yang terdapat dalam dirinya.

Demi mengembangkan potensi peserta didik, seluruh komponen pendidikan bekerja sama dalam mewujudkan hal tersebut. Sekolah merupakan satu kesatuan yang kompleks karena itu adanya guru BK atau konselor sekolah yang melayani siswa dengan pelayanan konseling. Melalui pelayanan konseling sebagai suatu 
bagian yang tak terpisahkan dari praktik pelaksanaan pendidikan diharapkan siswa mampu mengatasi permasalahan yang dialaminya.

Guru BK dengan pelayanan konselingnya memiliki beberapa pendekatan dan model konseling yang dapat diberikan kepada siswa dalam mengatasi masalah siswa serta mengembangkan kemampuan yang dialami siswa, baik secara individu, kelompok dan klasikal.Salah satunya adalah pendekatan konseling cognitive behavior therapy. Pelayanan konseling dengan menggunakan pendekatan cognitive behavior therapy setting kelompok dapat dilaksanakan kepada siswa.

Beck (1964) mendefenisikan cognitive behavior therapy sebagai pendekatan konseling yang dirancang untuk menyelesaikan permasalahan konseli pada saat ini dengan cara melakukan restrukturisasi kognitif dan perilaku yang menyimpang. Pendekatan cognitive behavior therapy didasarkan pada formulasi kognitif, keyakinan dan strategi perilaku yang menganggu. Proses konseling didasarkan pada konseptualisasi atau pemahaman konseli atas keyakinan khusus dan pola perilaku konseli. Cognitive behavior therapy didasarkan pada konsep mengubah pikiran dan perilaku negatif yang sangat mempengaruhi emosi. Melalui cognitive behavior therapy, konseli terlibat aktivitas dan berpartisipasi dalam kelompok untuk diri dengan cara membuat keputusan, penguatan diri dan startegi lain yang mengacu kepada self regulation dan self control (Matson dan Ollendick, 1988:44).

Matson dan Ollendick (1988:44) mendefenisikan cognitive behavior therapy suatu pendekatan dengan sejumlah prosedur yang secara spesifik menggunakan kognisi sebagai jalan utama terapi. National Association of Cognitive Behavioral Therapist (NACBT), mengungkapkan bahwa defenisi dari cognitive behavior therapy yaitu suatu pendekatan psikoterapi yang menekankan peran yang penting berpikir bagaimana individu merasakan dan apa yang individu lakukan (NACBT,2007). Cognitive behavior therapy didasarkan pada konsep mengubah pikiran dan perilaku negatif yang sangat mempengaruhi emosi. Melalui cognitive behavior therapy individu akan terlibat aktivitas dan partisipasi dalam kegiatan untuk diri dengan cara membuat keputusan, penguatan strategi lain yang mengacu kepada kontrol diri dan pengaturan diri (Matson dan Ollendick, 1988).

Pelaksanaan konseling cognitive behavior therapy dapat dilaksankan di lembaga formal seperti di sekolah, dalam hal ini peneliti mencoba melakukan penelitian konseling cognitive behavior therapy disalah satu sekolah yang berada di kabupaten Dharmasraya, dengan indikasi permasalah siswa memiliki kemampuan kontrol diri yang belum maksimal. Ini dilihat masih adanya siswa yang masih belum terampil dalam mengambil keputusan, mengontrol perilaku dan mengontrol pemikiran sehingga efek dari hal ini adalah pelanggaran aturan oleh siswa pada saat proses belajar mengajar di sekolah. Tujuan penelitian ini secara umum adalah untukmengetahui: (1) gambaranskor kontrol diri siswa sebelum (pre-test) dan setelah diberikan konseling cognitive behavior therapy (post-test), (2) menguji 
efektivitas pendekatan konseling cognitive behavior therapy untuk meningkatkan kontrol diri siswa.

Kontrol diri sederhananya dapat diartikan sebagai tenaga kontrol atas diri, oleh dirinya sendiri. Secara umum penjelasan para ahli tersebut memberikan pemaknaan bahwa kontrol diri adalah seperangkat kemampuan mendasar dan atribut personal yang melekat pada diri individu untuk mengatur tindakan yang akan membentuk pola prilaku dilingkungannya, yang meliputi aspek kognitif, afektif, dan psikomotorik. Penjelasan para ahli juga dapat mengandung makna bahawa kontrol diri merupakan kemampuan untuk menahan atau mengendalikan diri prilaku seseorang dengan mempertimbangkan berbagai kosekuensi dalam situasi tertentu agar mampu diterima dalam lingkungannya. Selain itu kontrol diri, dapat berdampak positif bagi secara personal, bagi pribadi yang memiliki kontrol diri, akan tetapi kontrol diri memiliki dampak positif secara luas dalam hubungan di lingkungannya (Marsela \& Supriatna, 2019).

\section{METODE PENELITIAN}

Desain penelitian yang digunakan dalam penelitian ini adalah penelitian eksperimen. Penelitian eksperimen adalah penelitian yang dilakukan dengan mengadakan manipulasi terhadap objek penelitian serta diadakannya kontrol terhadap variabel tertentu (Hasan, 2006). Eksperimen dalam penelitian ini adalah memberikan perlakuan layanan bimbingan kelompok kepada subjek penelitian. Tujuan dari penelitian ini adalah menyelidiki adanya hubungan sebab-akibat serta seberapa besar hubungan sebab-akibat tersebut dengan cara memberikan perlakuan-perlakuan tertentu pada kelompok eksperimental.

Jenis penelitian yang digunakan dalam penelitian ini adalah pre-eksperimen dengan The One Group Pre-test Post-test Design (Yusuf, 2013). Penelitian ini tidak menggunakan kelompok control karena hanya member perlakuan pada kelompok yang mengalami masalah. Subjek dalam penelitian ini dipilih menggunakan teknik non-random sampling, dengan metode purposive sampling (Arikunto, 2006), dalam penelitian ini subjek penelitian yang dipilih berdasarkan kontrol diri siswa yang rendah. Kontrol diri diketahui dari hasil pre-test. Sampel dalam penelitian ini sebanyak 10 siswa di SMK Negeri 1 Koto Baru Dharmasraya yang mengalami kontrol diri dengan kategori rendah dan sedang.

Instrumen yang digunakan dalam penelitian ini berupa angket dengan model skala likert. Instrumen penelitian ini telah lulus validasi dari beberapa ahli dan juga lulus ujireliabilitas di lapangan. Kondisi kontrol diri siswa akan dideskripsikan melalui norma kategori yang diklasifikasikan dengan kriteria sangat tinggi, tinggi, sedang, rendah dan sangat rendah. Menurut Azwar (2003) kategori dilakukan untuk menempatkan individu dalam kelompok-kelompok terpisah secara berjenjang menurut suatu kontinum berdasarkan atribut yang diukur. Adapun norma kategorisasi dalam penelitian ini dapat dilihat pada tabel 1 .

Hipotesis dalam penelitian ini adalah "Terdapat perbedaan rata-rata skor yang signifikan antara kontrol diri siswa sebelum (pre-test) dan setelah diberikan perlakuan konseling cognitive behavior therapy (post-test)". Hipotesis penelitian 
diuji menggunakan teknik analisis statistik non-parametrik, hal ini berdasarkan pada asumsi bahwa data di bawah 30 tidak berdistribusi normal. Teknik analisis statistik non-parametrik yang digunakan dalam penelitian ini adalah Uji Jenjang Bertanda Wilcoxon's (signed ranks test) (Siegel, 1997). Perlakuan atau konseling cognitive behavior therapy diberikan sebanyak 6 kali kepada subjek penelitian. Adapun langkah-langkah pelaksanaan konseling cognitive behavior therapy yang dilaksanakan antara lain: (1) assesmen dan diagnosa, (2) pendekatan cognitive,(3) formulasi status, (4)fokus konseling, (5) intervensi tingkah laku, (6) perubahan core beliefs.

Tabel 1. Norma Kategorisasi Kontrol Diri Siswa

\begin{tabular}{cc}
\hline Skor & Kategori \\
\hline $\mathrm{X} \leq 76$ & Sangat Rendah \\
$77<\mathrm{X} \leq 101$ & Rendah \\
$101<\mathrm{X} \leq 126$ & Sedang \\
$126<\mathrm{X} \leq 151$ & Tinggi \\
$151 \leq \mathrm{X}$ & Sangat Tinggi \\
\hline
\end{tabular}

Hipotesis dalam penelitian ini adalah "Terdapat perbedaan rata-rata skor yang signifikan antara kontrol diri siswa sebelum (pre-test) dan setelah diberikan perlakuan konseling cognitive behavior therapy (post-test)". Hipotesis penelitian diuji menggunakan teknik analisis statistik non-parametrik, hal ini berdasarkan pada asumsi bahwa data di bawah 30 tidak berdistribusi normal. Teknik analisis statistik non-parametrik yang digunakan dalam penelitian ini adalah Uji Jenjang Bertanda Wilcoxon's (signed ranks test) (Siegel, 1997). Perlakuan atau konseling cognitive behavior therapy diberikan sebanyak 6 kali kepada subjek penelitian. Adapun langkah-langkah pelaksanaan konseling cognitive behavior therapy yang dilaksanakan antara lain: (1) assesmen dan diagnosa, (2) pendekatan cognitive,(3) formulasi status, (4)fokus konseling, (5) intervensi tingkah laku, (6) perubahan core beliefs.

\section{HASIL PENELITIAN DAN PEMBAHASAN}

Berdasarkan data yang penelitiperoleh, maka hasil penelitian ini dapat dideskripsikan melalui pre-test dan post-test. Sesuai dengan tujuan dilakukannya pre-test, yaitu untuk mengetahui gambaran awal kondisi skor kontrol diri siswa sebelum diberikan perlakuan yaitu pendekatan konseling cognitive behavior therapy. Sedangkan post-test diberikan untuk melihat perubahan skor kontrol diri setelah subjek penelitian mendapat perlakuan. Hasil pengolahan data kepada 10 subjek penelitian (pada tahap pretest) menunjukkan sebagian besar berada pada kategori rendah, sebanyak 8 orang siswa termasuk kedalam kategori rendah yakni dengan perolehan skor pretest berada pada skor 80 sampai dengan 95. Sisanya sebanyak 2 orang termasuk ke dalam kategori sedang dengan hasil skor pretest 101 sampai dengan 103. Jika dilihat nilai rata-rata skor pretest yaitu sebesar 90. Kondisi ini mendekati kategori rendah. Artinya secara 
keseluruhan siswa yang diberikan perlakuan konseling cognitive behavior therapy mengalami permasalahan kontrol diri.

Dari data yang diperoleh pada posttest setelah diberikan perlakuan konseling cognitive behavior therapy dengan setting kelompok tidak terdapat siswa berada pada ketegori rendah. Sebanyak 9 siswa berada pada kategori tinggi, dan 1 orang siswa berada pada kategori sangat tinggi. Jika dilihat rata-rata skor, kondisi kontrol diri siswa berada pada skor 134 atau berada pada kategori tinggi. Untuk lebih jelas, berikut akan dipaparkan diagram batang hasil pretest dan posttest kontrol diri siswa.

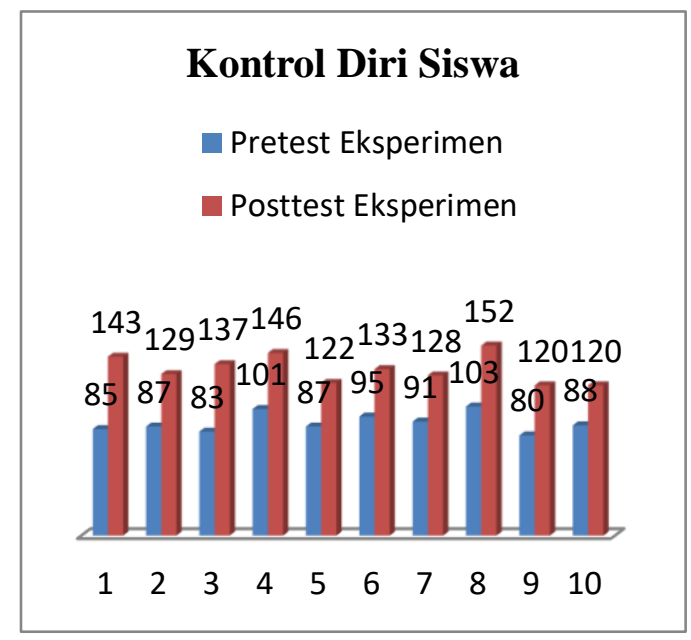

Gambar 1. Diagram Batang Hasil Pretest dan Posttest Kontrol Diri Siswa

Gambar 1 terlihat 10 subjek penelitian yang dilibatkan dalam perhitungan, mengalami peningkatan skor dari pretest ke posttest atau mengalami peningkatan kontrol diri setelah diberikan perlakuan yaitu pendekatan konseling cognitive behavior therapy. Pengujian hipotesis dilakukan dengan uji Wilcoxon's terhadap data pretest dan posttest. Untuk mengetahui apakah konseling cognitive behavior therapy dapat meningkatkan kontrol diri siswa disekolah dengan melihat perbedaan yang signifikan antara kondisi kontrol diri siswa pada pretest dan posttest, maka dilakukan pengujian terhadap hipotesis yang telah dirumuskan. 
Hasil analisis yang dirumuskan didapatkan nilai z 2.805, angka probabilitas Asymp. Sig.(2-tailed)kontrol diri subjek penelitian saat sebelum dan sesudah diberikan perlakuan sebesar 0.005, atau probabilitas di bawah alpha0.05 $(0.0025 \leq 0.05)$, dengan demikian hipotesis yang menyatakan "terdapat perbedaan yang signifikan antara ratarata skorkontrol diri siswa sebelum(pretest) dan setelah diberikan perlakuan konseling cognitive behavior therapy(posttest) dapat diterima".

\section{PEMBAHASAN}

Paparan hasil pengujian hipotesis yang berbunyi "Terdapat perbedaan skor rata-rata pada control diri siswa sebelum (pretest) dansetelah (posttest) diberikankonseling cognitive behavior therapy dengan format kelompok, dimana skor rata-rata posttest lebih tinggi secara signifikan dibandingkan pretest."Berdasarkan data dapat diartikan kontrol diri siswa meningkat setelah diberikan bimbingan kelompok cognitive behavior therapy.

Kontrol diri siswa adalah hal yang penting dimiliki oleh siswa, oleh karenanya perlu suatu upaya untuk membantu siswa meningkatkan kontrol dirinya. Konseling cognitive behavior therapy merupakan salah satu dari sekian banyak pendekatan dalam bimbingan konseling yang dirancang untuk menyelesaikan permasalahan konseli pada saat ini dengan cara melakukan restrukturisasi kognitif dan perilaku yang menyimpang (Beck, 1964). Proses konseling didasarkan pada konseptualisasi atau pemahaman konseli atas keyakinan khusus dan pola perilaku konseli. Harapan dari cognitive behavior therapy yaitu munculnya restrukturisasi kognitif dan perilaku ke arah yang lebih baik.

Melalui format kelompok pendekatakan cognitive behavior therapy yang dilaksanakan lima sesi dengan topik-topik: (1) makna dan pentingnya kontrol diri, (2) makna dan pentingnya mengontrol perilaku dengan topik menjadi siswa teladan di sekolah, (3) belajar menjadi pribadi yang mandiri, (4) mengambil keputusan yang tepat, dan(5) tanggung jawab. Terbukti bahwa kontrol diri lebih meningkat dengan adanya pendekatankonseling cognitive behavior therapy dalam kehidupan sehari-harinya. Dalam penelitian ini layanan bimbingan kelompok dengan menggunakan teknik SMART (specific, dapat dinilai, memiliki makna, dan terukur waktunya menjadikan siswa belajar untuk berperilaku control diri.

Kenyataan di atas sesuai dengan pendapat Wilding dan Milne (2013) yang menyatakan model pendidikan cognitive behavior therapy mengajari individu untuk menjadi diri sendiri, yang digunakan dalam kehidupan sehari-hari sesuai dengan semua permasalahan dalam kehidupan individu agar mampu mengontrol pikiran dan melalukan perilaku yang terkontrol sehingga dapat meningkatkan 
kualitas hidup. Cognitive behavior therapy akan memberikan efek untuk meningkatkan kontrol diri dalam berbagai situasi, maka anak yang sering mengatur pola pikir yang positif maka perilaku control diri akan terbentuk dengan baik, baik dalam kehidupan nyata sebenarnya maupun dalam proses belajar.

Kontrol diri dapat terjadi dimana saja dan kapan saja. Kontrol diri juga akan terjadi di lingkungan sekolah. Kemampuan siswa dalam melakukan kontrol diri antara siswa yang satu dengan siswa yang lain tidak sama. Siswa yang memiliki kemampuan kontrol diri yang tinggi, dapat terlihat dari sikap tidak melanggar aturan sekolah, berpikir sebelum bertindak yang akan dilakukan, mampu mengontrol keputusan, dan tanggung jawab dari semua perbuatan yang dilakukan di sekolah. Sehingga akan mudah menjalani kehidupan sosial di lingkungannya dan ia tidak akan mengalami hambatan dalam berinteraksi dengan lingkungan di sekitarnya. Sebaliknya siswa yang memiliki kemampuan kontrol diri yang rendah akan mengalami hambatan dalam kehidupan sosialnya. Sering melanggar aturan sekolah, tidak mampu mengontrol tindakan diri, dan kurang mampu mengontrol keputusan.

Adanya perbedaan antara hasil pretest dan posttest pada subjek penelitian setelah diberikan pendekatan konseling cognitive behavior therapy dengan format kelompok. Menurut Prayitno dan Amti (2004), bimbingan kelompok bertujuan secara khusus, diantaranya; 1) melatih siswa untuk dapat mengendalikan diri dalam kegiatan kelompok, 2) melatih siswa untuk dapat bersikap tenggang rasa dengan orang lain, 3) melatih siswa memperoleh keterampilan sosial dan 4) membantu siswa mengenali dan memahami dirinya dalam hubungannya dengan orang lain.

\section{KESIMPULAN}

Secara umum hasil penelitian ini dapat disimpulkan sebagai berikut: (1) Terdapat perbedaan yang signifikan antara rata-rata skor kontrol diri siswa sebelum dan sesudah diberikan perlakuan pendekatan konseling konseling cognitive behavior therapy. Kontrol diri siswa mengalami peningkatan setelah diberikan perlakuan pendekatan konseling cognitive behavior therapy.(2) Pendekatan konseling cognitive behavior therapy efektif untuk meningkatkan kontrol diri siswa. Saran yang dapat peneliti berikan sebagai berikut dari hasil penelitian ini yakni : (1) Guru bimbingan dan konseling diharapkan memberikan pelayanan lebih lanjut kepada subjek penelitian inisebagai upaya menjalankan fungsi pengembangan dan pemeliharaan. Tindak lanjut dapat dilakukan dengan memberikan berbagai materi tentang peningkatan kepercayaan diri, hubungan sosial, dan pemahaman tentang potensi diri. Disarankan pula agar memberikan pelayanan kepada siswa-siswa yang mengalami kontrol diri yang rendah sebagai upaya menjalankan fungsi kuratif. (2)Bagi kepala sekolah, hasil penelitian ini dapat menjadi masukan untuk mendukung pelaksanaan pelayanan BK selanjutnya bagi siswa-siswa yang mengalami masalah 
dengan potensi lainnya. Upaya kepala sekolah dalam membantu guru bimbingan dan konseling dalam melaksanakan fungsi pengembangan dan pemeliharaan akan memberikan dampak yang positif pada situasi belajar mengajar di sekolah. (3) Bagi peneliti selanjutnya, perlu melakukan penelitian longitudinal (jangka panjang) denganmenggunakan pendekatan konseling cognitive behavior therapy untuk meningkatkan kontrol diri, dalam rangka melanjutkan, mengembangkan,menambah ilmu pengetahuan untuk keperluan pendidikan dan keilmuan yang lebih luas. Pendekatan konseling cognitive behavior therapy sangat berguna untuk meningkatkan kontrol diri siswa dan untuk terapi-terapi lainnya dalam menumbuh kembangkan potensi peserta didik, (4) Bagi peserta didik, setelah mengikuti bimbingan kelompok dengan pendekatan cognitive behavior therapy siswa termotivasi, untuk meningkatkan kontrol dirinya, juga mengembangkan sikap berfikir sebelum bertindak, mampu membuat keputusan yang tepat, dan mampu mengontrol perilaku di sekolah dan dilingkungan sekitar.

\section{DAFTAR PUSTAKA}

Arikunto, S. (2006). Prosedur Penelitian Suatu Pendekatan Praktik. Rineka Cipta.

Azwar, S. (2003). Penyusunan Skala Psikologi. Pustaka Pelajar.

Beck, A.T. (1964). "Thinking and Depression: II. Theory and Therapy. Archives of General Psychiatry". Journal Psychological, 10: 561-571.

Borba, M. (2001). Building Moral Intelligence the Seven Essential Vitues That Teach Kids to Do the Right Thing (Membangun Kecerdasan Moral Tujuh Kebijakan Anak Bermoral Tinggi).Terjemahan oleh LinaJusuf. 2008. Gramedia Pustaka Utama.

Calhoun, J. F., dan Acocella, J. R. (1976). Psychology of Adjustment and Human Relationship (Psikologi tentang Penyesuaian dan Hubungan Kemanusian).Terjemahan oleh R.S Satmoko. 1990. IKIP Semarang Press.

Hasan, I. (2006). Analisis Data Penelitian dengan Statistik. Bumi Aksara.

National Asocication Cognitive Behavioral Therapy (NACBT). (2007). "Cognitive Behavioral Therapy". Journal Psychological. Tersedia:http//www.nacbt.or/whatiscbt.htm. diakses 28 Juli 2015.

Matson, J. L., dan Ollendick, T. H. (1988). Enhancing Children's Social Skill: Assesment and Training. Pergamon Press.

Marsela, R. D., dan Supriatna, M. (2019). Kontrol Diri: Definisi dan Faktor. Journal of Innovative Counseling: Theory, Practice \& Research. 
Prayitno. (1995). Layanan Bimbingan dan Konseling Kelompok (Dasar dan Profil). Ghalia Indonesia.

Prayitno, dan Erman, A. (2004). Dasar-dasar Bimbingan Konseling. Rineka Cipta.

Siegel, S. (1997). Statistika Nonparametrik untuk Ilmu-ilmu Sosial. Gramedia.

Undang-undang dan Peraturan Pemerintah RI tentangPendidikan. (2006). Direktorat Jendral Pendidikan Islam Departemen Agama RI.

Wilding, C., dan Milne, A. (2010). Cognitive Behavior Therapy.Terjemahan oleh Ahmad Fuandy. 2013. Indeks.

Yusuf, A .M. (2008). Dasar-dasar Metode Penelitian. UNP Press. 